\title{
Effect of deposition temperature on the structural and optical properties of chemically prepared nanocrystalline lead selenide thin films
}

\author{
Anayara Begum*, Amir Hussain and Atowar Rahman
}

Open Access

\begin{abstract}
Nanocrystalline lead selenide ( $\mathrm{PbSe}$ ) thin films were prepared on glass substrates by a chemical bath deposition method, using sodium selenosulfate $\left(\mathrm{Na}_{2} \mathrm{SeSO}_{3}\right)$ as a source of $\mathrm{Se}^{2-}$ ions, and lead acetate as a source of $\mathrm{Pb}^{2+}$ ions. Trisodium citrate (TSC) was used as a complexing agent. PbSe films were prepared at various deposition temperatures while the pH value was kept fixed at 11 , and the effect on the resulting film properties was studied by X-ray diffraction (XRD), X-ray fluorescence (XRF), scanning electron microscopy (SEM) and optical absorption studies. The structural parameters, such as the lattice constant (a), crystallite size $(D)$, dislocation density $(\rho)$ and microstrain $(\varepsilon)$ were evaluated from the XRD spectra. It was found that average crystallite size, as calculated from Scherrer's formula, increased from 23 to $33 \mathrm{~nm}$ as the deposition temperature was varied from 303 to $343 \mathrm{~K}$. The dislocation density and microstrain were found to vary inversely with the crystallite size, whereas the lattice constant was found to increase with an increase in crystallite size. The optical absorption spectra of the nanocrystalline PbSe films showed a blue shift, and the optical band gap $\left(E_{\mathrm{g}}\right)$ was found to increase from 1.96 to $2.10 \mathrm{eV}$ with the decrease in crystallite size.
\end{abstract}

\section{Introduction}

Lead selenide $(\mathrm{PbSe})$ with its narrow band gap $\left(E_{\mathrm{g}}=0.27 \mathrm{eV}\right)$ [1] is an important semiconductor of the IV-VI lead chalcogenides group. PbSe has a large exciton Bohr radius (46 nm), which offers the opportunity to achieve strong size quantization at relatively large crystal size $[2,3]$. PbSe has wide applications in long and mid-wavelength infrared detectors, optical amplifiers, mid-infrared lasers, as thermoelectric materials, and as $\mathrm{Pb}^{2+}$ ion selective sensors [4-7]. Among the various techniques used to prepare $\mathrm{PbSe}$ thin films, such as vacuum evaporation [8], microwave heating [9], pulsed laser deposition [10], electrochemical atomic layer epitaxy [11], and electrodeposition [12], the chemical bath deposition method [13,14] is relatively simple and cost-effective, and has the advantage that it allows control over deposition parameters such as the $\mathrm{pH}$, the concentration of ions, deposition temperature, etc., with great ease. 
In this paper we report the preparation of nanocrystalline $\mathrm{PbSe}$ thin films by the chemical bath method at different deposition temperatures and at a fixed $\mathrm{pH}$ value, and we discuss the dependence of various structural and optical properties on the deposition temperature.

\section{Experimental}

Lead selenide thin films were deposited by using lead acetate $\left(\mathrm{Pb}\left(\mathrm{CH}_{3} \mathrm{COO}\right)_{2}\right)$ and freshly prepared sodium selenosulfate $\left(\mathrm{Na}_{2} \mathrm{SeSO}_{3}\right)$ as $\mathrm{Pb}^{2+}$ and $\mathrm{Se}^{2-}$ ions source, respectively, in the presence of trisodium citrate (TSC) as a complexing agent. The $\mathrm{Na}_{2} \mathrm{SeSO}_{3}$ solution was prepared by mixing $3 \mathrm{~g}$ selenium powder with $30 \mathrm{~g}$ anhydrous sodium sulfite in $150 \mathrm{ml}$ of distilled water under constant stirring for $8-10 \mathrm{~h}$ at $353 \mathrm{~K}$ [15].

To prepare thin films of $\mathrm{PbSe}, 0.5 \mathrm{M} \mathrm{Pb}\left(\mathrm{CH}_{3} \mathrm{COO}\right)_{2}$ solution was prepared. To this solution was added $1 \mathrm{M}$ TSC solution, and then the $\mathrm{pH}$ of the solution was adjusted to 10.80 by dropwise addition of $\mathrm{KOH}$. Finally, $\mathrm{Na}_{2} \mathrm{SeSO}_{3}$ was added and the $\mathrm{pH}$ of the final deposition bath was adjusted to 11 . The glass substrates were vertically immersed in the deposition bath at the desired temperature. After a deposition period of $2 \mathrm{~h}$, the substrates were taken out, rinsed in distilled water and dried. Four different sets of $\mathrm{PbSe}$ films were prepared at different temperatures $(328,333,338$, and $343 \mathrm{~K})$. The as-deposited films were uniform, continuous, and pinhole free. These were specularly reflective, and extremely adherent to the substrates. However the PbSe films prepared at room temperature (303 K) were found to be pale brown in appearance.

The X-ray diffraction patterns of the as-deposited PbSe thin films were taken on an X-ray diffractometer (XPERT PRO Philips) at room temperature. Studies of the surface morphology of the chemically deposited PbSe films were achieved by scanning electron microscope (JEOL JSM 6360).
The X-ray fluorescence study (XRFS) was performed on an AXIOS spectrometer (DY 840) for elemental analysis of the as-prepared films and optical absorption studies were carried out using a UV-vis spectrophotometer (VARIAN CARY 300 scan) in the wavelength range $360-900 \mathrm{~nm}$. The thickness of the PbSe thin films was measured by the multiple beam interferometer technique.

\section{Results and Discussion Film growth}

A PbSe thin film is formed when the ionic product of $\mathrm{Pb}^{2+}$ and $\mathrm{Se}^{2-}$ ions exceeds the solubility product of $\mathrm{PbSe}\left(\approx 10^{-38}\right.$ at $300 \mathrm{~K})$ [16]. The deposition process is based on the slow release of $\mathrm{Pb}^{2+}$ and $\mathrm{Se}^{2-}$ ions in the solution. The complexing agent trisodium citrate controls the $\mathrm{Pb}^{2+}$ concentration and slowly releases $\mathrm{Pb}^{2+}$ ions into the solution. The proposed reaction mechanism for formation of PbSe thin films is as follows,

$$
\begin{gathered}
{\left[\mathrm{Pb}(\mathrm{A})_{n}\right]^{2+} \longrightarrow \mathrm{Pb}^{2+}+n \mathrm{~A}} \\
\mathrm{Na}_{2} \mathrm{SeSO}_{3}+2 \mathrm{OH}^{-} \longrightarrow \mathrm{Na}_{2} \mathrm{SO}_{4}+\mathrm{Se}^{2-}+\mathrm{H}_{2} \mathrm{O} \\
\mathrm{Pb}^{2+}+\mathrm{Se}^{2-} \longrightarrow \mathrm{PbSe}
\end{gathered}
$$

where A is trisodium citrate.

\section{X-ray diffractograms}

Typical XRD patterns obtained from films grown at different temperatures and at pH 11 are shown in Figure 1. The observed " $d$ " spacings and the respective prominent peaks correspond to reflections of the (111), (200), (220), (311), (222), (331), (420) and (422) planes and are in good agreement with the standard data (JCPDS No. 06-0354). Thus, the XRD pattern reveals the
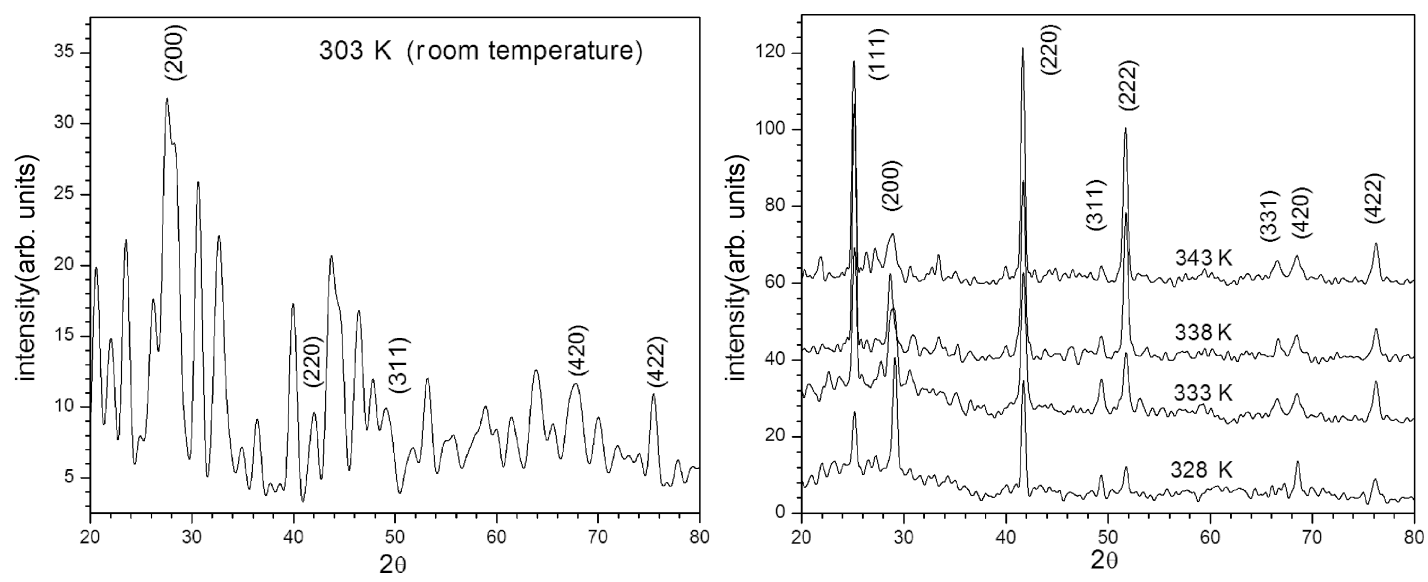

Figure 1: X-ray diffraction patterns of $\mathrm{PbSe}$ thin films prepared at different temperatures. 
polycrystalline nature of the as-deposited $\mathrm{PbSe}$ thin films with cubic structure.

The most intense peak for each of the samples prepared at 328 , 333,338 , and $343 \mathrm{~K}$ corresponds to (200), (111), (111) and (220), respectively. This indicates that the orientation of the grain growth for PbSe films prepared at different temperatures is along different directions. The XRD pattern of $\mathrm{PbSe}$ prepared at room temperature (303 K) shows peaks for (200), (220), (420) and (422) in addition to several other peaks, which are mainly due to impurity phases (such as $\mathrm{Pb}, \mathrm{Se}, \mathrm{PbO}$, or other $\mathrm{Pb}$ compounds).

\section{Crystallite size}

The average crystallite size of $\mathrm{PbSe}$ thin films prepared at different temperatures calculated using Scherrer's formula [17] was found to increase from 23 to $33 \mathrm{~nm}$ with an increase of temperature from 303 to $343 \mathrm{~K}$, as shown in Figure 2. The rate of the deposition reaction increases at higher temperature and the crystallites grow faster resulting in a larger size.

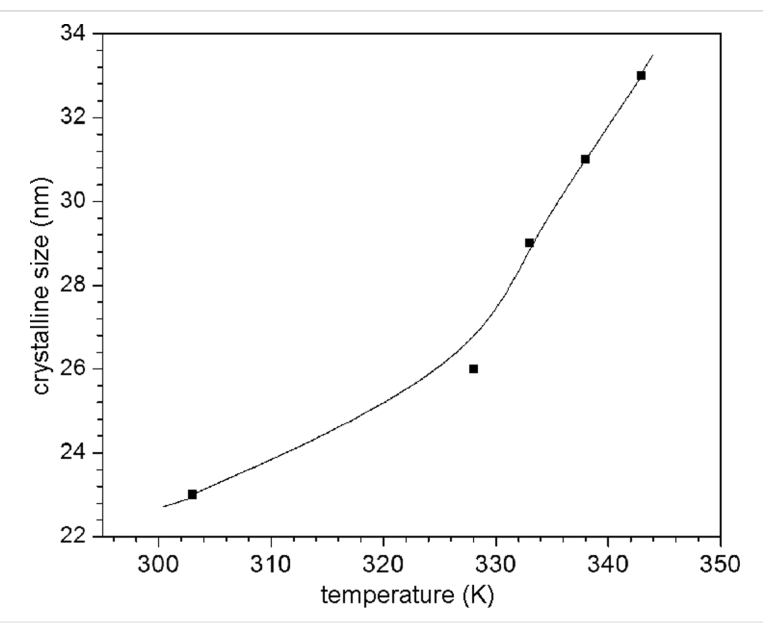

Figure 2: Variation of the average crystallite size of $\mathrm{PbSe}$ thin films with the deposition temperature.

\section{Lattice constant}

The lattice parameter " $a$ " for cubic structure was determined by using the relation

$$
a=d\left(h^{2}+k^{2}+l^{2}\right)^{1 / 2}
$$

where " $d$ " is the spacing between the planes in the atomic lattice, and $(h k l)$ are the Miller indices. The lattice constant values are found to be slightly different for different orientations of the same film. The probable explanation for this was given by Mothura et al. [18]. Therefore, corrected values of the lattice constants were determined from the intercept of the
Nelson-Riley plots. The Nelson-Riley curve is plotted between the calculated " $a$ " for different planes and the error function [19]

$$
f(\theta)=\frac{1}{2}\left[\frac{\cos ^{2} \theta}{\sin \theta}+\frac{\cos ^{2} \theta}{\theta}\right]
$$

and the corrected value of " $a$ " is obtained by extrapolating the plot to $\theta=90^{\circ}$. A typical Nelson-Riley plot for a PbSe thin film is shown in Figure 3.

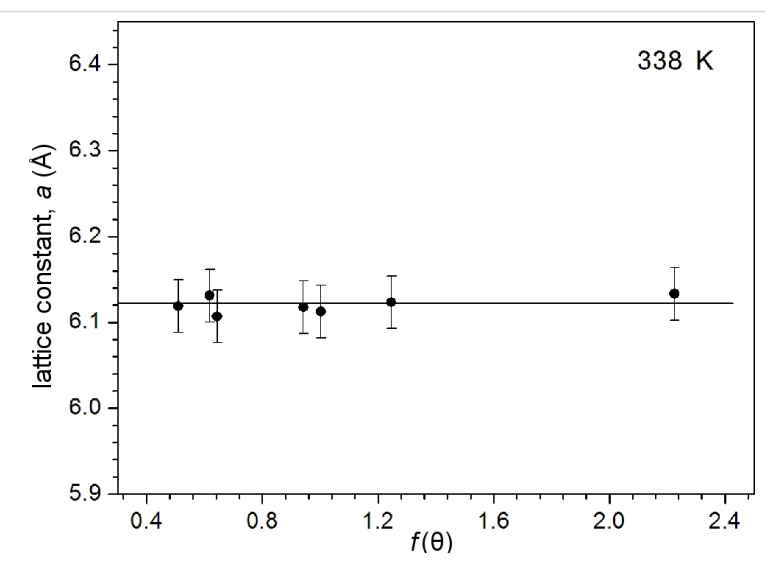

Figure 3: Nelson-Riley plot for PbSe thin film prepared at $338 \mathrm{~K}$.

The lattice parameter is observed to increase slightly from 6.112 to $6.129 \AA$ with deposition temperature. All the values of lattice constant of the as-prepared PbSe thin films were found to be different from the values of the bulk material (6.124 A, JCPDS 06-0354). The deviation in the values of the lattice constant of the as-prepared $\mathrm{PbSe}$ films from the bulk value indicates the presence of strain in the films. The strain in the prepared $\mathrm{PbSe}$ films may arise due to the change of lattice nature and concentration of native imperfections during the film formation.

\section{Dislocation density $(\delta)$ and microstrain $(\varepsilon)$}

The dislocation density $(\delta)$ was calculated from Williamson and Smallman's formula [20]

$$
\delta=\frac{n}{D^{2}}
$$

where " $n$ " is a factor, which when equal to unity gives the minimum dislocation density, and " $D$ " is the average crystallite size. The average microstrain $(\varepsilon)$ developed in the as-prepared PbSe films was calculated by using the relation [21]

$$
\varepsilon=\frac{\beta \cot \theta}{4}
$$


where " $\beta$ " is the full width at half maximum and $\theta$ is the Bragg angle.

It has been observed that the dislocation density and microstrain decrease with increase in crystallite size, as shown in Figure 4, which indicates a lower number of lattice imperfections. This may be due to a decrease in the occurrence of grain boundaries because of an increase in the crystallite size of the film with increasing temperature.
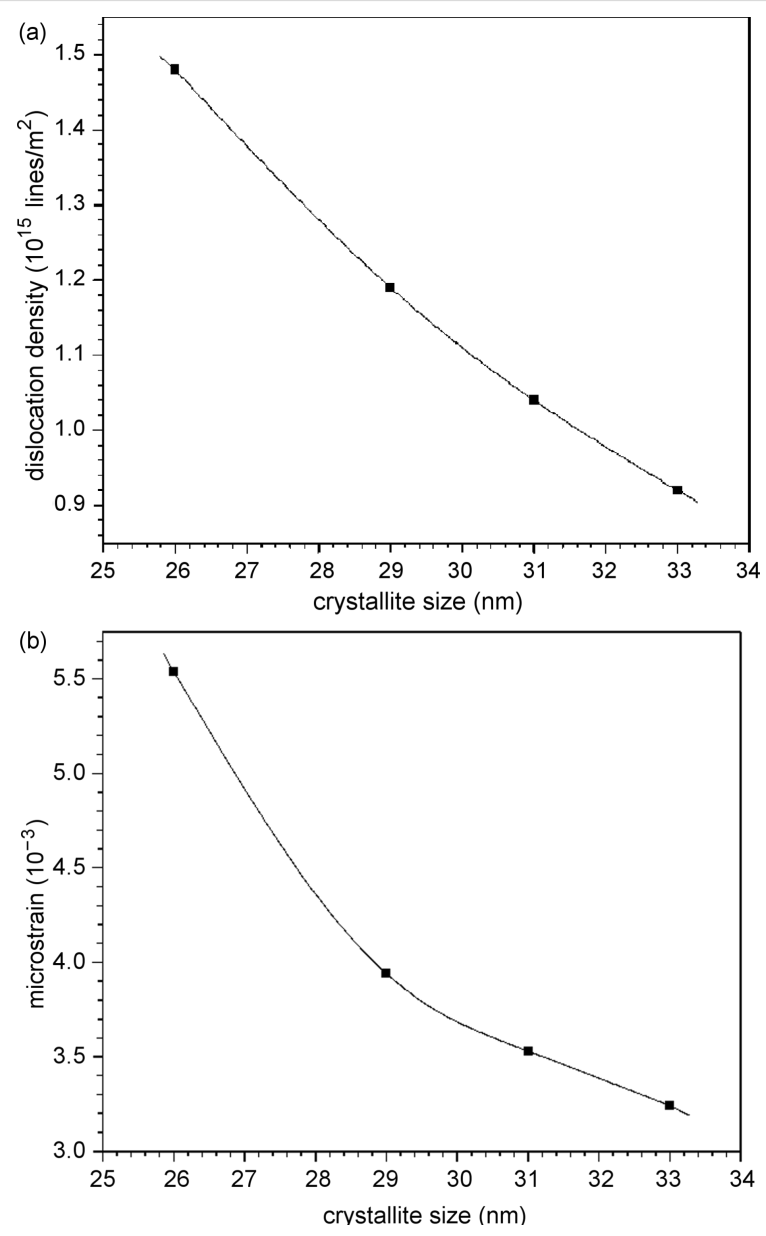

Figure 4: Variation of (a) dislocation density and (b) microstrain with crystallite size of the PbSe thin films.

\section{Surface morphology}

Scanning electron microscopy gives valuable information regarding the shape and size of the grains on the surface of the deposited thin films. Figure 5a shows the SEM image of PbSe thin films prepared at $303 \mathrm{~K}$ (room temperature), and reveals cube-like structures, which are aggregated. From the SEM image of PbSe prepared at $338 \mathrm{~K}$ (Figure 5b) and $343 \mathrm{~K}$ (Figure 5c), it was observed that the PbSe thin films consisted of spherical grains and were homogenous, without any voids or cracks. (a)

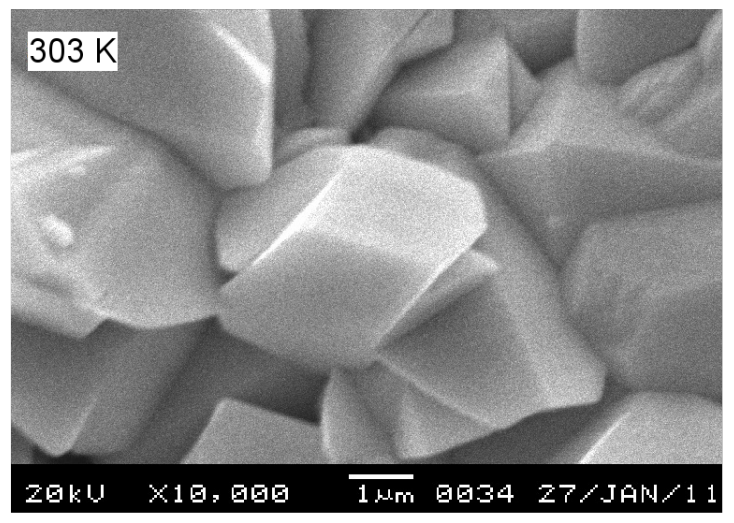

(b)

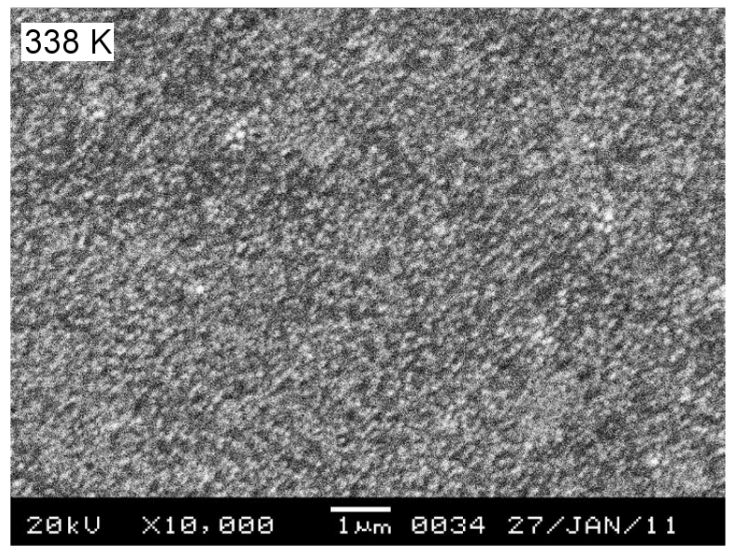

(c)

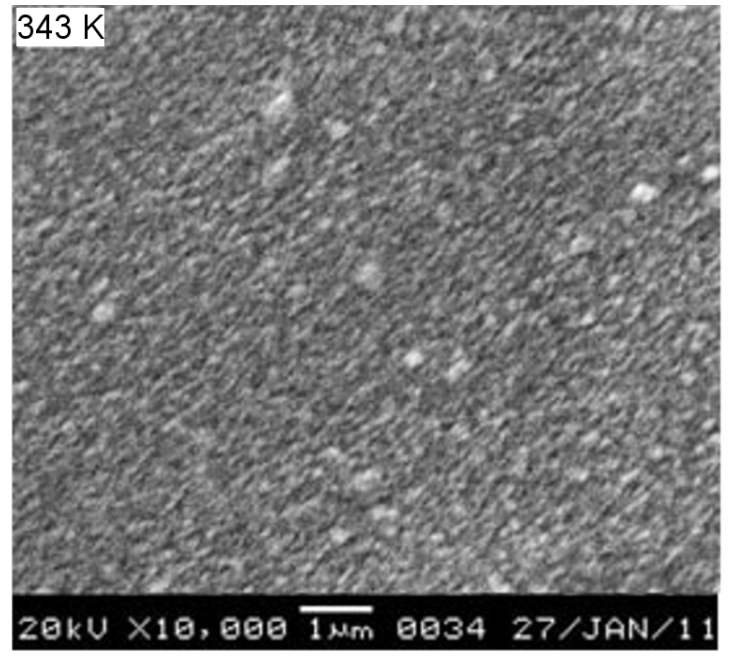

Figure 5: SEM micrograph of PbSe prepared at (a) $303 \mathrm{~K}$ (b) $338 \mathrm{~K}$ and (c) $343 \mathrm{~K}$.

The crystallite size obtained by XRD is equivalent to the mean size of the domains that scatter X-rays coherently [22]. The grain size measured from SEM images is the surface morphology of grains that are agglomerated crystallites, leading to larger values of grain size. 


\section{X-ray fluorescence (XRF) studies}

Figure 6 shows the XRF spectra of PbSe thin films prepared at $333 \mathrm{~K}$. The spectrum exhibits prominent peaks of the $\mathrm{Pb} \mathrm{L} \beta$, $\mathrm{Pb} \mathrm{L} \alpha_{1}, \mathrm{~Pb} \mathrm{~L} \alpha_{2}$ and $\mathrm{Se} K \alpha_{1}$ lines showing the presence of $\mathrm{Pb}$ and $\mathrm{Se}$ in the prepared films.

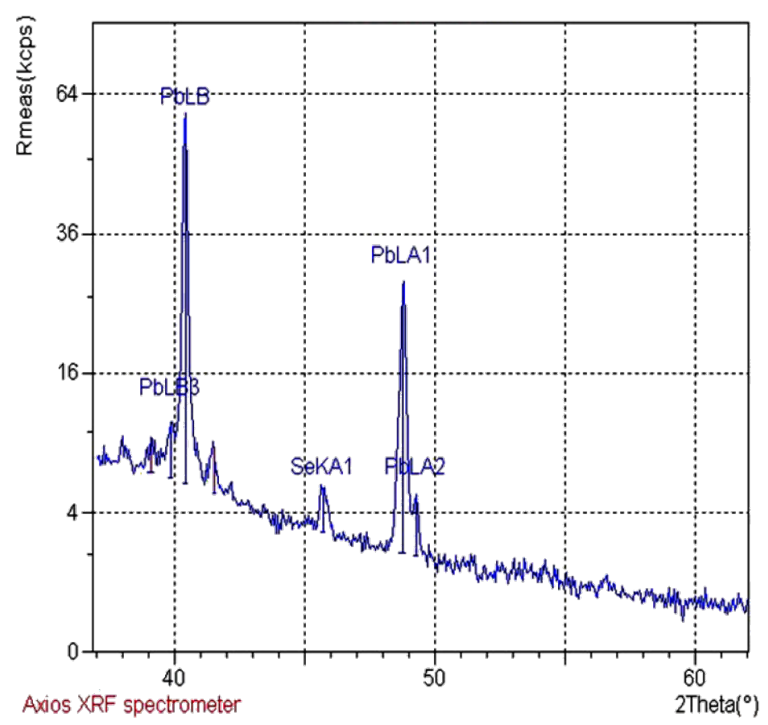

Figure 6: XRF spectra of $\mathrm{PbSe}$ prepared at $333 \mathrm{~K}$.

\section{Optical properties}

The absorption spectra of $\mathrm{PbSe}$ thin films recorded at room temperature as a function of wavelength in the range 360-900 nm, is shown in Figure 7a. It shows that the optical absorption of PbSe thin films increases with the deposition temperature. This may be attributed to the increase in crystallite size and decrease in defects. The $(\alpha h v)^{2}$ versus $(h v)$ plots of $\mathrm{PbSe}$ thin films are linear over a wide range of photon energies, as shown in Figure $7 \mathrm{~b}$. This indicates the presence of a direct optical band gap in the as-prepared PbSe thin films [23]. The

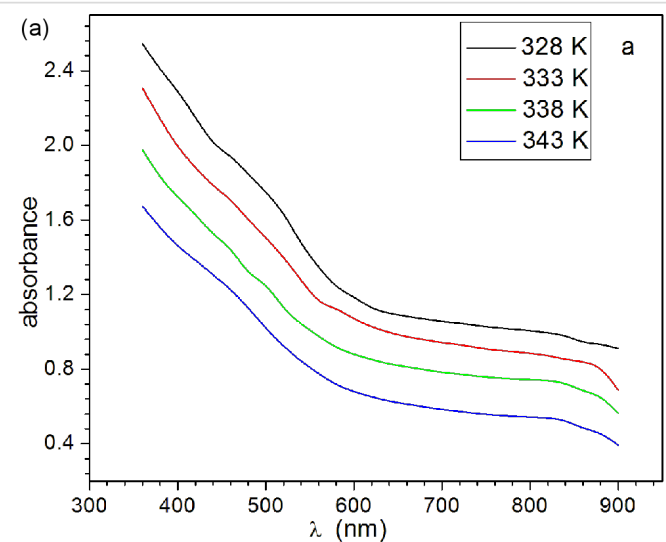

optical band gap of these films was obtained by extrapolating the linear portion of the curve to the energy axis.

The band gap so obtained was observed to decrease from 2.10 to $1.96 \mathrm{eV}$, as the deposition temperature was increased from 328 to $343 \mathrm{~K}$. Typical variation of band gap with crystallite size in the nanocrystalline PbSe thin films is shown in Figure 8, which indicates an increase in the band gap with a decrease in crystallite size (the structural parameters and band-gap energies are also summarized in Table 1). Clearly, the observed values of $E_{\mathrm{g}}$ are higher than the value of the bulk optical band gap of PbSe [0.27 eV] [1] due to quantum confinement in the nanocrystalline $\mathrm{PbSe}$ thin films. Similar changes in the band gap energy " $E_{\mathrm{g}}$ " for $\mathrm{PbSe}$ thin films with smaller crystallite sizes have been reported for chemically deposited PbSe thin films by Gorer et al. [24]. The value of the band gap was found to vary from 0.55 to $1.55 \mathrm{eV}$, depending on the crystallites size, by Gorer et al.

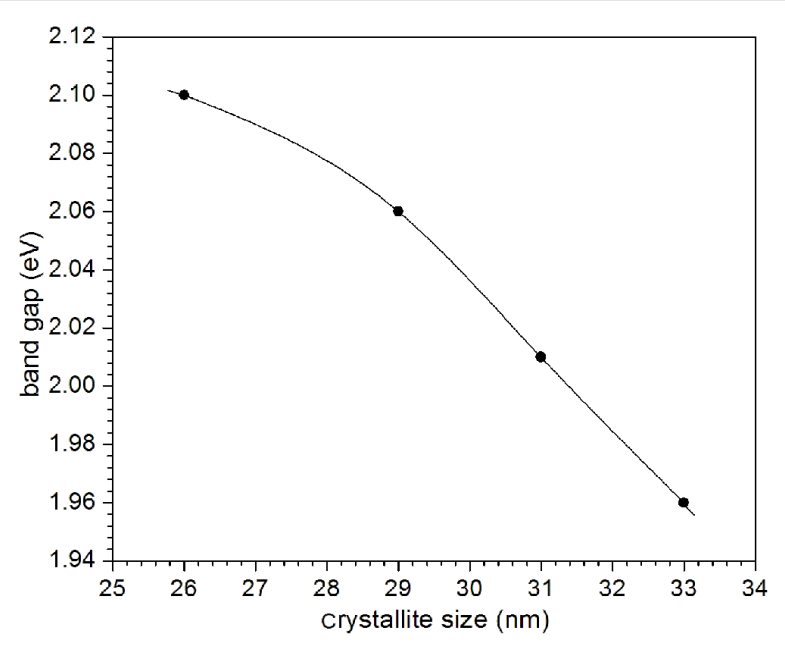

Figure 8: Variation of the band gap with crystallite size of PbSe thin films.

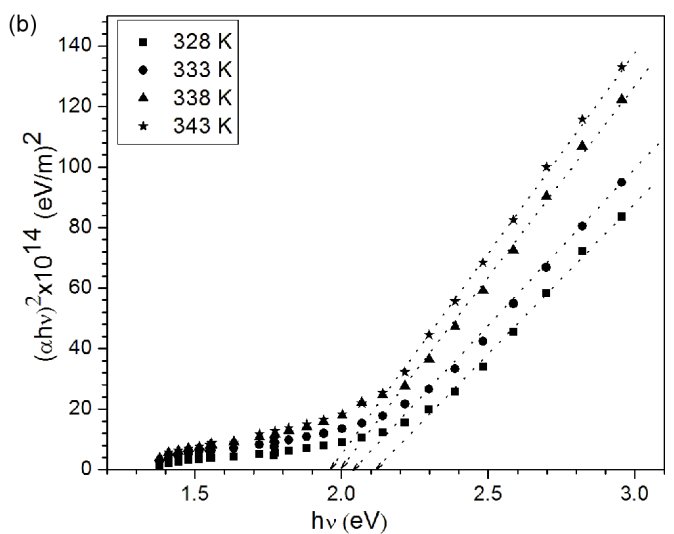

Figure 7: (a) UV absorption spectra; (b) ( $\alpha h v)^{2}$ vs (hv) plots of PbSe thin films. 
Table 1: Structural parameters and band-gap energies of PbSe thin films deposited at different temperatures.

\begin{tabular}{lllllll}
$\begin{array}{l}\text { SI } \\
\text { no. }\end{array}$ & $\begin{array}{l}\text { deposition } \\
\text { temperature }(\mathrm{K})\end{array}$ & $\begin{array}{l}\text { average crystallite } \\
\text { size }(\mathrm{nm})\end{array}$ & $\begin{array}{l}\text { lattice } \\
\text { constant }(\AA)\end{array}$ & $\begin{array}{l}\text { microstrain } \\
(\varepsilon) \times 10^{-3}\end{array}$ & $\begin{array}{l}\text { dislocation density } \\
(\delta)\left(\times 10^{15} \text { lines }^{2} \mathrm{~m}^{2}\right)\end{array}$ & $\begin{array}{l}\text { band gap }\left(E_{\mathrm{g}}\right) \text { from } \\
\text { absorption } \mathrm{spectra}(\mathrm{eV})\end{array}$ \\
\hline 1 & 328 & 26 & 6.112 & 5.54 & 1.48 & 2.10 \\
2 & 333 & 29 & 6.121 & 3.94 & 1.19 & 2.04 \\
3 & 338 & 31 & 6.122 & 3.53 & 1.04 & 2.00 \\
4 & 343 & 33 & 6.129 & 3.24 & 0.92 & 1.96
\end{tabular}

\section{Conclusion}

Nanocrystalline PbSe thin films have been successfully deposited at different temperatures (328 to $343 \mathrm{~K}$ ) above room temperature $(303 \mathrm{~K})$. The grains were found to be spherical in shape and the crystallite sizes found from XRD increased from 26 to $33 \mathrm{~nm}$ as the deposition temperature was increased from 328 to $343 \mathrm{~K}$. The optical band gap of the PbSe films was found to increase from 1.96 to $2.10 \mathrm{eV}$ with the decrease in crystallite size, which is in accordance with the quantum confinement effect. The dislocation density and microstrain were found to decrease with increase in deposition temperature and, hence, crystallite size, indicating the improvement of $\mathrm{PbSe}$ thin films.

\section{References}

1. Gao, S.; Liu, D.; Xu, D.; Li, D.; Hong, Y.; Chen, H.; Dai, Q.; Kan, S.; Li, H.; Zou, G. Smart Mater. Struct. 2007, 16, 2350-2353. doi:10.1088/0964-1726/16/6/039

2. Sashchiuk, A.; Amirav, L.; Bashouti, M.; Krueger, M.; Sivan, U.; Lifshitz, E. Nano Lett. 2004, 4, 159-165. doi:10.1021/nl0345116

3. Murray, C. B.; Sun, S.; Gaschler, W.; Doyle, H.; Betley, T. A.; Kagan, C. R. IBM J. Res. Dev. 2001, 45, 47-56. doi:10.1147/rd.451.0047

4. Allan, G.; Delerue, C. Phys. Rev. B 2004, 70, 245321. doi:10.1103/PhysRevB.70.245321

5. Shen, W. Z.; Wang, K.; Jiang, L. F.; Wang, X. G.; Shen, S. C.; Wu, H. Z.; McCann, P. J. Appl. Phys. Lett. 2001, 79, 2579-2581. doi:10.1063/1.1406988

6. Lee, M.-H.; Chung, W. J.; Park, S. K.; Kim, M.-s.; Seo, H. S.; Ju, J. J. Nanotechnology 2005, 16, 1148-1152. doi:10.1088/0957-4484/16/8/028

7. Yamamoto, O.; Sasamoto, T.; Inagaki, M. J. Mater. Res. 1998, 13, 3394-3398. doi:10.1557/JMR.1998.0462

8. Kumar, S.; Khan, Z. H.; Majeed Khan, M. A.; Husain, M. Curr. Appl. Phys. 2005, 5, 561-566. doi:10.1016/j.cap.2004.07.001

9. Zhu, J.; Palchik, O.; Chen, S.; Gedanken, A. J. Phys. Chem. B 2000, 104, 7344-7347. doi:10.1021/jp001488t

10. Rumianowski, R. T.; Dygdala, R. S.; Jung, W.; Bala, W. J. Cryst. Growth 2003, 252, 230-235. doi:10.1016/S0022-0248(02)02528-9

11. Vaidyanathan, R.; Stickney, J. L.; Happek, U. Electrochim. Acta 2004, 49, 1321-1326. doi:10.1016/j.electacta.2003.07.019

12. Saloniemi, H.; Kanniainen, T.; Ritala, M.; Leskelä, M.; Lappalainen, R. J. Mater. Chem. 1998, 8, 651-654. doi:10.1039/a706471c

13. Gorer, S.; Albu-Yaron, A.; Hodes, G. Chem. Mater. 1995, 7, 1243-1256. doi:10.1021/cm00054a027
14. Bhardwaj, A.; Srivastava, P.; Sehgal, H. K. J. Electrochem. Soc. 2007, 154, K83-K86. doi:10.1149/1.2763963

15. Kale, R. B.; Lokhande, C. D. Appl. Surf. Sci. 2004, 223, 343-351. doi:10.1016/j.apsusc.2003.09.022

16. Hankare, P. P.; Delekar, S. D.; Bhuse, V. M.; Garadkar, K. M.; Sabane, S. D.; Gavali, L. V. Mater. Chem. Phys. 2003, 82, 505-508. doi:10.1016/S0254-0584(03)00375-4

17. Cullity, B. D. Elements of X-ray diffraction, 2nd ed.; Addison-Wesley Publishing Company, Inc.: CA, USA, 1978; pp 327-335.

18. Borah, M. N.; Chaliha, S.; Sarmah, P. C.; Rahman, A. Optoelectron. Adv. Mater. Rapid Commun. 2008, 2, 342-348.

19. Nelson, J. B.; Riley, D. P. Proc. Phys. Soc., London 1945, 57, 160. doi:10.1088/0959-5309/57/3/302

20. Lifshim, E. X-ray characterization of materials; Wiley: New York, 1999; p 37.

21. Girija, K.; Thirumalairajan, S.; Mohan, S. M.; Chandrasekaran, J. Chalcogenide Lett. 2009, 6, 351-357.

22. Ungár, T.; Tichy, G.; Gubicza, J.; Hellmig, R. J. Powder Diffr. 2005, 20, 366-375. doi:10.1154/1.2135313

23. Joshi, R. K.; Kanjilal, A.; Sehgal, H. K. Nanotechnology 2003, 14, 809-812. doi:10.1088/0957-4484/14/7/320

24. Gorer, S.; Albu-Yaron, A.; Hodes, G. J. Phys. Chem. 1995, 99 , 16442-16448. doi:10.1021/j100044a036

\section{License and Terms}

This is an Open Access article under the terms of the Creative Commons Attribution License (http://creativecommons.org/licenses/by/2.0), which permits unrestricted use, distribution, and reproduction in any medium, provided the original work is properly cited.

The license is subject to the Beilstein Journal of Nanotechnology terms and conditions: (http://www.beilstein-journals.org/bjnano)

The definitive version of this article is the electronic one which can be found at: doi:10.3762/bjnano. 3.50 